\title{
SISTEM INFORMASI PENGELOLAAN DATA LAUNDRY PADA RUMAH LAUNDRY BEKASI
}

\author{
Susy Rosyida1; Verry Riyanto² \\ Program Studi Teknik Informatika ${ }^{1,2}$ \\ Sekolah Tinggi Manajemen Informatika dan Komputer Nusa Mandiri ${ }^{1,2}$ \\ www.nusamandiri.ac.id \\ susyrosyida@gmail.com ${ }^{1}$, verry.vry@nusamandiri.ac.id ${ }^{2}$
}

\begin{abstract}
Laundry house is a business engaged in services in washing and drying, especially clothing. To serve the public in the field of laundry services, the laundry house in managing the data is still done manually and has not been computerized so there are still errors in the transaction process. Problems that occur in a laundry house such as incorrectly recording the type of package, the calculation is still using a calculator tool, in making the report must see the notes that have been collected previously, must see previous records recorded in the ledger, and be vulnerable to losing previous note notes so that it takes a long time and the results obtained are less accurate. The purpose of this study is to build a laundry data management program using the waterfall method which consists of 5 stages, namely, software requirements analysis, design, programming code, testing and support or maintenance. While the data collection is through observation, interviews and searching for literature related to this research so that it can solve problems related to laundry data management activities, especially in the process of receiving laundry services transactions to be more effective and efficient and can improve service to customers. The results of the study show that this laundry data management program can help and simplify the process of receiving laundry services at the laundry house.
\end{abstract}

Keywords: Information Systems, Laundry Data Management, Laundry Houses.

Intisari- Rumah laundry adalah suatu usaha yang bergerak di bidang jasa dalam pencucian dan pengeringan terutama pakaian. Untuk melayani masyarakat dalam bidang jasa laundry, rumah laundry dalam pengelolahan datanya masih dilakukan secara manual belum terkomputerisasi sehingga masih terjadi kesalahan-kesalahan dalam proses transaksinya. Permasalahan yang terjadi pada rumah laundry seperti salah mencatat jenis paket, perhitungannya masih menggunakan alat bantu kalkulator, dalam pembuatan laporannya harus melihat nota-nota yang telah dikumpulkan sebelumnya, harus melihat catatan sebelumnya yang dicatat di buku besar, dan rentan kehilangan nota-nota catatan sebelumnya sehingga membutuhkan waktu yang lama dan hasil yang didapat kurang akurat. Tujuan penelitian ini adalah membangun program pengelolaan data laundry menggunakan metode waterfall yang terdiri dari 5 tahapan yaitu, analisis kebutuhan perangkat lunak, desain, pembuatan kode program, pengujian dan pendukung atau pemeliharaan. Sedangkan pengumpulkan datanya melalui observasi, wawancara dan mencari literature-literature yang berhubungan dengan penelitan ini sehingga dapat memecahkan permasalahan-permasalahan yang berkaitan dengan aktivitas pengelolaan data laundry terutama dalam proses transaksi penerimaan jasa laundry menjadi lebih efektif dan efisien serta dapat meningkatkan pelayanan kepada pelanggan. Hasil penelitian menunjukan program pengelolaan data laundry ini dapat membantu serta mempermudah proses transaksi penerimaan jasa laundry pada rumah laundry.

Kata Kunci: Sistem Informasi, Pengelolaan Data Laundry, Rumah Laundry.

\section{PENDAHULUAN}

Perkembangan dunia saat ini membuat kehidupan seseorang banyak melakukan kegiatan dalam perkembangan karirnya. Kesibukan seseorang dalam melakukan pekerjaan ataupun pemilik bisnis (Helling, 2018) serta padatnya jadwal kegiatan seseorang, akan mempengaruhi pola hidup seseorang dalam segala hal, sebagai contoh untuk melakukan hal yang mudah saja seperti halnya mencuci dan menyetrika pakaiannya (Sari, Handayani, \& Saufi, 2017) tidak bisa dilakukan karena kesibukannya tersebut, bahkan ketika ada waktu luang mereka lebih memilih utuk istirahat atau melakukan kegiatan lain untuk refreshing dalam rangka menghilangkan kejenuhan. Oleh karena itu, usaha di bidang penerimaan jasa laundry saat ini juga ikut berkembang pesat, sehingga dapat memudahkan orang-orang yang memiliki kesibukan 
(Frediyatma, 2014) serta jadwal kegiatan yang padat serta masyarakat pada umumnya dalam hal mencuci dan menyetrika pakaian mereka. Dengan adanya jasa laundry ini, konsumen akan mendapatkan beberapa keuntungan, antara lain akan menghemat waktu, tenaga, dan biaya.

Pada awal munculnya jasa laundry, jasa laundry masih menggunakan adminstrasi secara manual (Saggaf, Salam, Kahar, \& Akib, 2014) dan sederhana dalam pencatatan order maupun administrasi keuangannya. Kemudian karena banyaknya jasa laundry yang muncul menjadi persaingan di sektor ini semakin ketat. (Khoirunnissa, Isnanto, \& Martono, 2016). Oleh karena itu tiap-tiap jasa laundry akan berusaha meningkatkan pelayanan kepada konsumen agar tidak ditinggalkan oleh konsumen tersebut. Kemajuan teknologi informasi dan komputer seiring dengan perkembangan zaman dan pesatnya pertumbuhan teknologi informasi dan komputer juga berdampak kepada jasa laundry yang kemudian mulai mengaplikasikan teknologi informasi dan komputer dalam memberikan pelayanan yang lebih baik kepada para konsumen dalam hal pencatatan order dan administrasi keuangannya, agar dapat memenuhi tuntutan masyarakat saat ini yang menginginkan sesuatu dengan cepat bahkan instan.

Pelayanan yang kurang memuaskan akan menyebabkan berkurangnya konsumen atau bahkan hilang karena konsumen berpindah ke jasa layanan yang lainnya (Fatmawati, 2016) penerimaan jasa laundry adalah jasa yang paling tepat dan sesuai dengan kondisi masyarakat pada saat ini terutama yang tinggal di perkotaan, jasa laundry ini untuk membantu masyarakat ketika tidak bisa melakukan hal mencuci dan menyetrika karena kesibukan pekerjaan dan padatnya jadwal kegiatan seseorang. Sebuah jasa laundry akan berusaha melakukan administrasi penerimaan order dan administrasi keuangan serta tugas pencuciannya dengan baik. Pengolahan data manual sangat rentan terhadap kesalahan penulisan, kerusakan, kehilangan data, dan penumpukan berkas yang memerlukan ruang yang luas (Puspitasari, 2014). Proses transaksi penerimaan jasa laundry ini pada awalnya masih dilakukan secara manual (Khoirunnissa et al., 2016) sehingga memungkinkan terjadi kesalahankesalahan yang terjadi dalam proses pengolahan data (Andharsaputri, 2019) seperti salah mencatat jenis paket atau order, perhitungannya masih secara manual (Hasugian, 2019)atau mungkin menggunakan alat bantu kalkulator, kemudian dalam pembuatan laporannya harus melihat notanota yang telah dibuat dan dikumpulkan sebelumnya, serta harus melihat catatan sebelumnya yang dicatat di buku besar, dan yang tidak kalah pentingnya juga hal ini akan rentan kehilangan data (Karman \& Nurhasan, 2019) atau nota-nota catatan sebelumnya sehingga memerlukan waktu yang lama dan hasil yang didapat kurang maksimal.

Salah satu strategi yang mutlak dimiliki adalah penggunaan aplikasi dalam membantu kegiatan bisnis agar berjalan efektif dan efisien (Dewi, Kurniati, \& Irmayani, 2017) dengan diterapkannya transaksi yang manual akan memiliki tingkat keamanan dan perhitungan yang rentan dengan kesalahan sehingga hasilnya kurang cepat dan akurat. Tujuan penelitian ini adalah membangun program pengelolaan data laundry menggunakan metode waterfall. Apabila diterapkan sistem yang terkomputerisasi dalam proses pengelolaan data laundry, hal ini akan memudahkan proses transaksi baik pengguna maupun pelanggan dalam proses transaksi agar hasil yang didapat lebih cepat dan akurat. Memudahkan pemilik dalam mengelola bisnisnya, serta membantu karyawan dalam pengolahan transaksi (Kirlyana \& Rosyida, 2016).

\section{BAHAN DAN METODE}

Pada metode penelitian yang digunakan dalam pengembangan perangkat lunak pada penelitan ini yaitu model waterfall (Sukamto \& Shalahuddin, 2015) yang terbagi menjadi lima tahapan pada Gambar 1 .

\section{A. Analisis Kebutuhan Perangkat Lunak}

Tahapan ini diawali dengan perencanaan dan analisa terhadap kebutuhan, menganalisa kebutuhan yang dipergunakan yaitu analisa kebutuhan pengguna yang terdiri dari administrator dan kasir, serta analisa kebutuhan sistem.

\section{B. Desain}

Setelah tahapan analisa kebutuhan terpenuhi, kemudian melakukan perancangan Entity Relationship Diagram untuk merancang tabel-tabel (Sulianta \& Umbara, 2015) dengan menggunakan MySQL dalam basis data sesuai kebutuhan, mendesain antarmuka dan HIPO sebagai dokumentasi program.

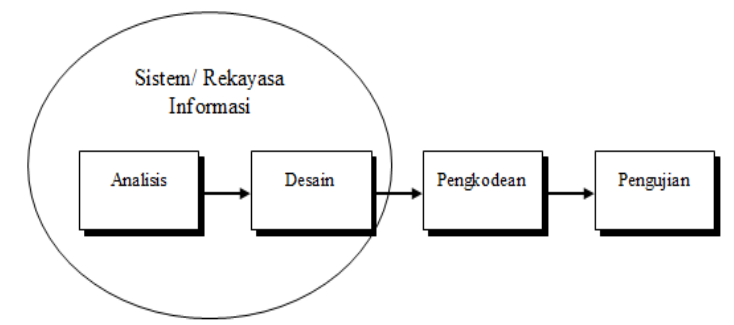

Sumber: (Sukamto \& Shalahuddin, 2015) Gambar 1. Ilustrasi Model Waterfall 


\section{Pembuatan Kode Program}

Dalam tahapan ini membuat kode program pada setiap form menggunakan bahasa pemrograman Microsoft Visual Studio Visual Basic. Net 2010 untuk membedakan fungsi dari kode tersebut dan untuk mempermudah memproses data.

D. Pengujian

Pada tahap pengujian ini, memastikan bahwa program yang dibuat sudah bekerja dengan baik tanpa adanya error atau bug terhadap program yang dibuat dalam Microsoft Visual Studio Visual Basic. Net 2010.

E. Pendukung (support) atau pemeliharaan (maintenance)

Dalam tahap ini dilakukan pengembangan program sebelumnya agar selalu mengikuti perkembangan teknologi yang ada sehingga selalu update.

\section{HASIL DAN PEMBAHASAN}

Pengolahan data secara komputerisasi menggunakan suatu program sangat dibutuhkan untuk menunjang pekerjaan yang berkaitan dengan proses pengolahan data baik dibidang bisnis, industri, perusahaan, maupun pendidikan. Saat ini masih banyak instansi yang menggunakan sistem manual dalam menjalankan usahanya. Seperti dalam mengolah data sampai pada pembuatan laporan masih dilakukan secara manual. Sehingga membutuhkan waktu yang lama dan kurang efektif. Untuk mempermudah melakukan proses transaksi, diperlukan sebuah program pengolahan data laundry untuk memudahkan pengguna dalam proses transaksi pengolahan data khususnya proses penyimpanan data pengguna, penyimpanan data pelayanan jasa laundry, penyimpanan data transaksi penerimaan jasa laundry, sampai dengan pembuatan laporan. Sistem informasi pengolahan data laundry ini menggunakan fase-fase model waterfall. Adapun hasil dan pembahasan dari penelitian ini:

\section{A. Analisis Kebutuhan Perangkat Lunak}

Kebutuhan perangkat lunak yang dibutuhkan terdiri dari 2 pengguna, yaitu kasir dan administrasi. Masing-masing pengguna diberikan akses sesuai dengan kebutuhannya masingmasing.

1. Kebutuhan kasir dapat mengelola data pelanggan, melakukan transaksi pengolahan data laundry, dapat mengolah data laporan laundry.

2. Kebutuhan administrasi dapat mengelola data laundry, mengelola data pelanggan, melakukan transaksi pengolahan data laundry, dapat mengolah data laporan laundry.

\section{B. Desain}

Pada tahap desain ini dilakukan desain database dan desain antarmuka sistem informasi pengolahan data laundry.

Desain sistem yang digunakan pada sistem informasi Pengolahan Data Laundry yaitu menggunakan UML, karena bahasa pemodelan yang menurut penulis mudah dipahami dan mudah digunakan. Diagram yang digunakan pada sistem informasi ini yaitu usecase diagram, di mana rancangan menampilam aktor yang melakukan transaksi pengguna sistem yaitu kasir dan administrasi. Gambar 2 merupakan rancangan usecase diagramnya. Desain database yang digunakan pada sistem informasi pengolahan data laundry ini menggunakan Entity Relationship Diagram (ERD). Pada Gambar 3, menjelaskan tentang Entity Relationship Diagram (ERD) dalam pembuatan program sistem informasi pengolahan data laundry yang terdiri dari 6 (enam) entitas yaitu pengguna, pelanggan, paketlaundry, penyerahan, pengambilan, detailtransaksi.

Berdasarkan hasil penelitian yang telah dilakukan maka dibuatkan program untuk pengelolaan data laundry dengan tampilan pada Gambar 4. Gambar 4 merupakan tampilan saat pertama kali ingin masuk ke dalam program pengelolaan data laundry pada rumah laundry.

Gambar 5 merupakan tampilan menu utama, dimana ada menu file, master, transaksi, laporan dan ganti kata sandi untuk admin dalam mengelola data laundry. Gambar 7 merupakan tampilan untuk menginput data transaksi pada saat penyerahan untuk dilaundry. Gambar 6 merupakan tampilan untuk menambahkan data paket laundry pada rumah laundry. Gambar 8 merupakan tampilan untuk menginput data transaksi pada saat pengambilan setelah dilaundry. Gambar 9 merupakan tampilan untuk mengganti kata sandi atau password pengguna pada program pengelolaan data laundry.

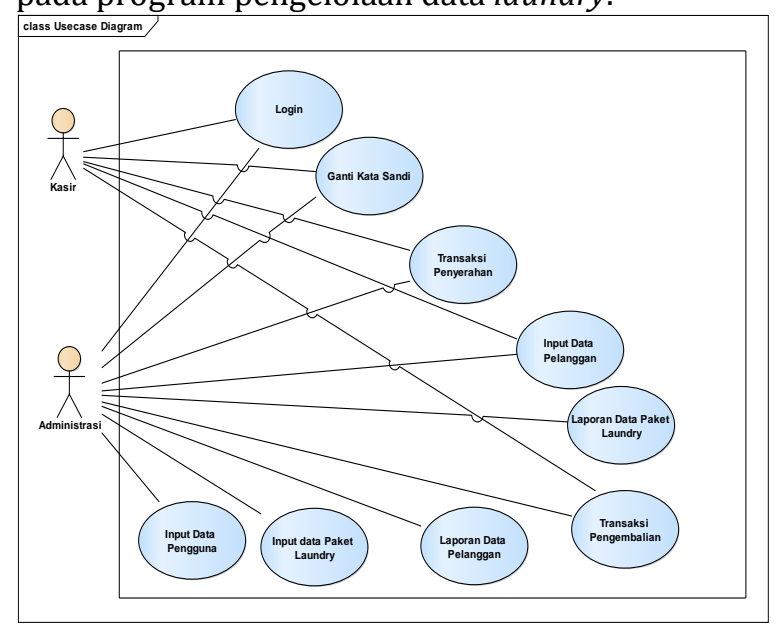

Gambar 2. Usecase Diagram Pengolahan Data Laundry 


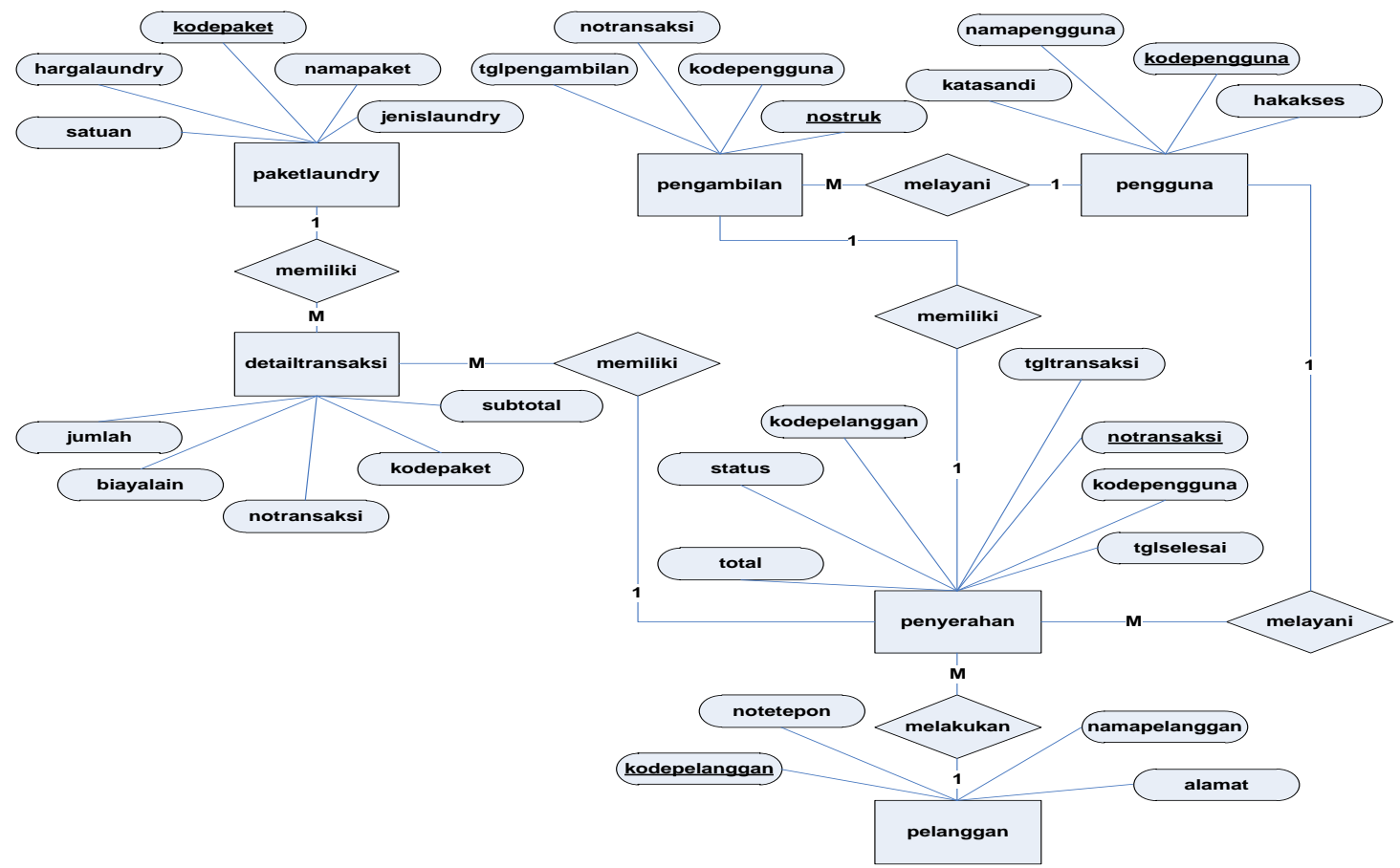

Gambar 3. ERD Pengolahan Data Laundry

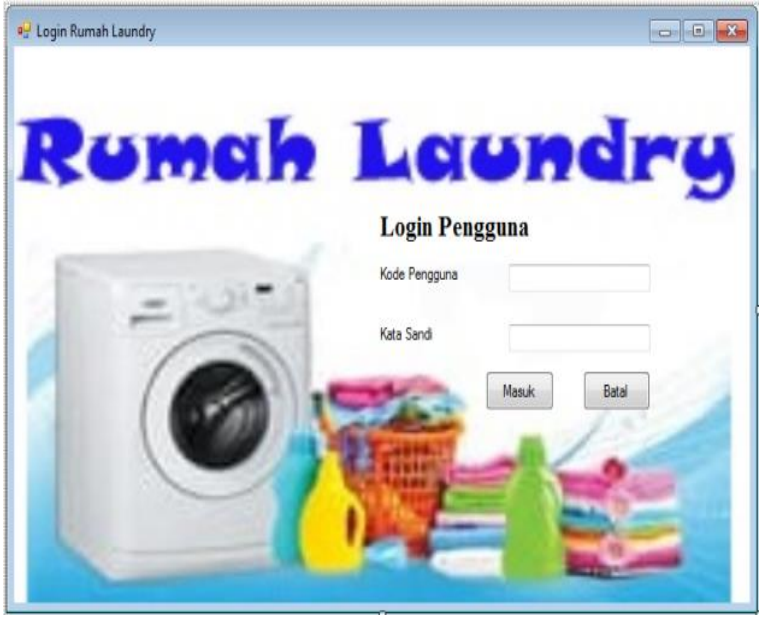

Gambar 4. Tampilan Halaman Login

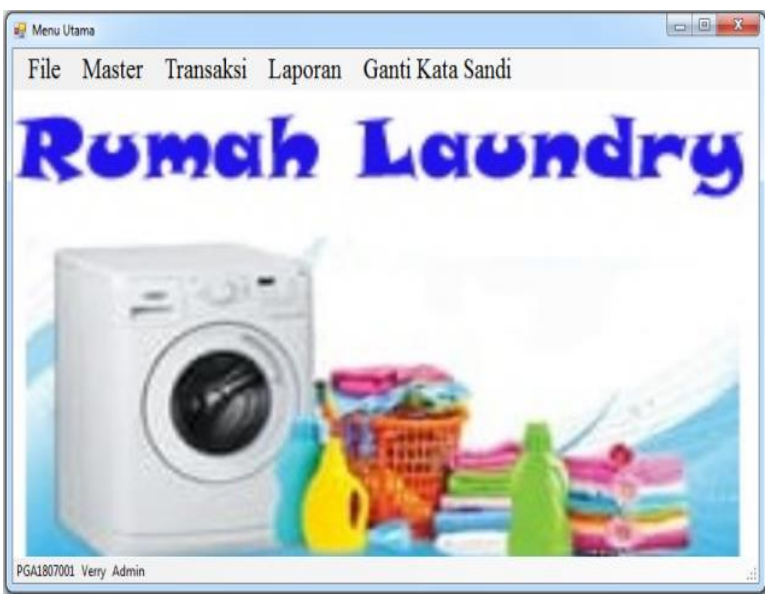

Gambar 5. Tampilan Menu Utama

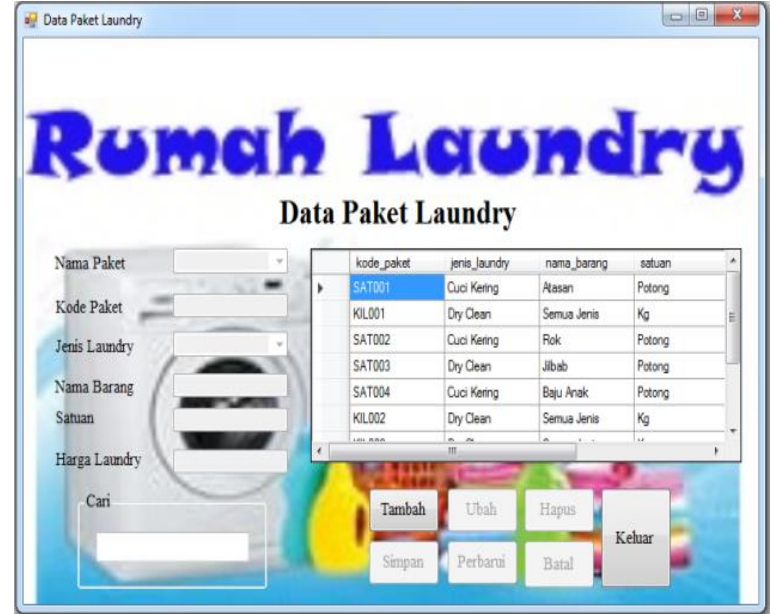

Gambar 6. Tampilan Data Paket Laundry

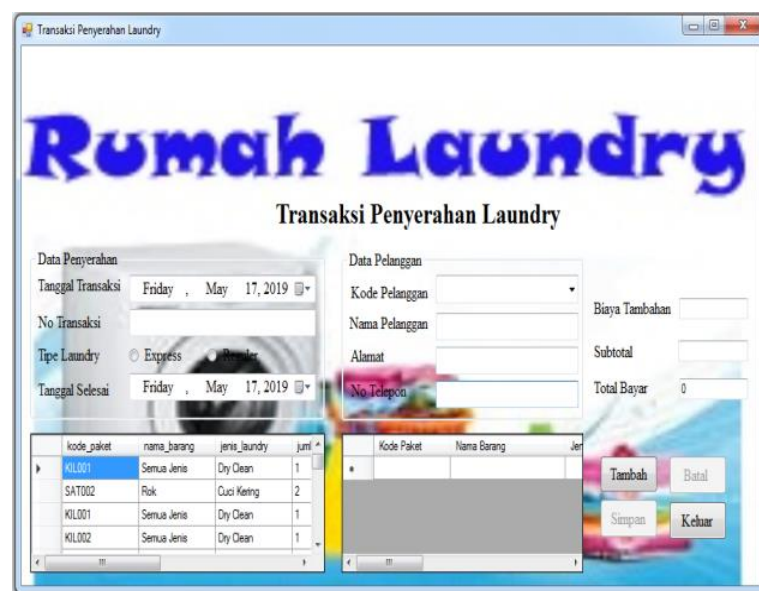

Gambar 7. Tampilan Transaksi Penyerahan Laundry 


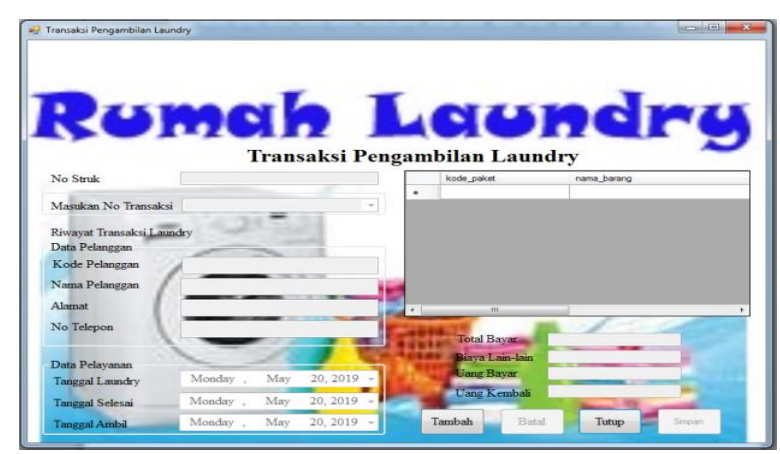

Gambar 8. Tampilan Transaksi Pengambilan Laundry

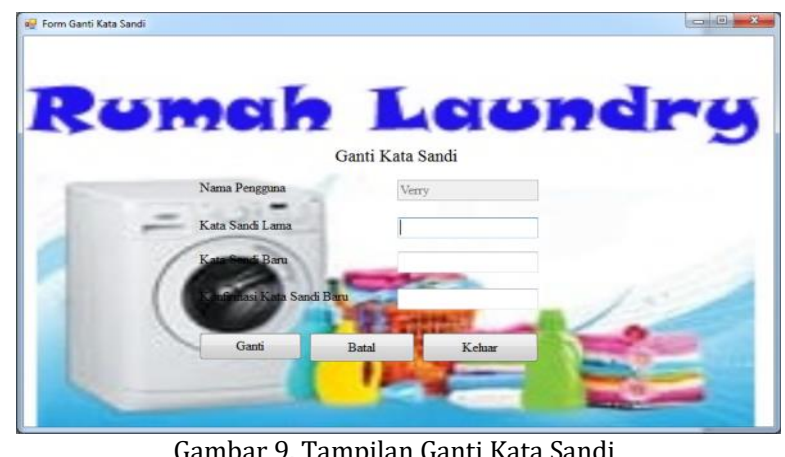

Gambar 10 merupakan laporan untuk melihat data paket yang ada di rumah laundry. Gambar 11 merupakan laporan untuk melihat data paket yang ada di rumah laundry.
HIPO (Hierarchy plus Input-Proses-Output) adalah alat dokumentasi program. Akan tetapi sekarang, HIPO (Hierarchy plus Input-ProsesOutput) juga banyak digunakan sebagai alat desain dan teknik dokumentasi dalam siklus pengembangan sistem (Hartono, 2017). HIPO dalam penelitian ini seperti gambar 12 .

\begin{tabular}{|c|c|c|c|c|c|}
\hline \multicolumn{2}{|c|}{ Rumah Laundry } & \multicolumn{4}{|c|}{$\begin{array}{c}\text { DATA PAKET RUMAH LAUNDRY } \\
\text { JL. Merak III No. } 115 \\
\text { Kelurahan Teluk Pucung, Kecamatan Bekasi Utara } \\
\text { No. Telp. } 08561742903\end{array}$} \\
\hline \multicolumn{6}{|c|}{ Tanggal : 12 Desember 2018} \\
\hline Kode Paket & Nama Paket & Jenis Laundry & Nama Barang & Satuan & Harga \\
\hline KIL001 & Kiloan & Dry Clean & Semua Jenis & $\mathrm{Kg}$ & Rp. 12.000 \\
\hline KIL002 & Kiloan & Dry Clean & Semua Jenis & $\mathrm{Kg}$ & Rp. 12.000 \\
\hline KIL003 & Kiloan & Dry Clean & Semua Jenis & $\mathrm{Kg}$ & Rp. 12.000 \\
\hline SAT001 & Satuan & Cuci Kering & Atasan & Potong & Rp. 4.000 \\
\hline SAT002 & Satuan & Cuci Kering & Rok & Potong & Rp. 3.000 \\
\hline SAT003 & Satuan & Dry Clean & Jilbab & Potong & Rp. 4.000 \\
\hline SAT004 & Satuan & Cuci Kering & Baju Anak & Potong & Rp. 4.000 \\
\hline SAT005 & Satuan & Cuci Kering & Baju & Potong & Rp. 3.000 \\
\hline SAT006 & Satuan & Dry Clean & Kaos & Potong & Rp. 3.000 \\
\hline
\end{tabular}

Gambar 10. Laporan Data Paket Laundry

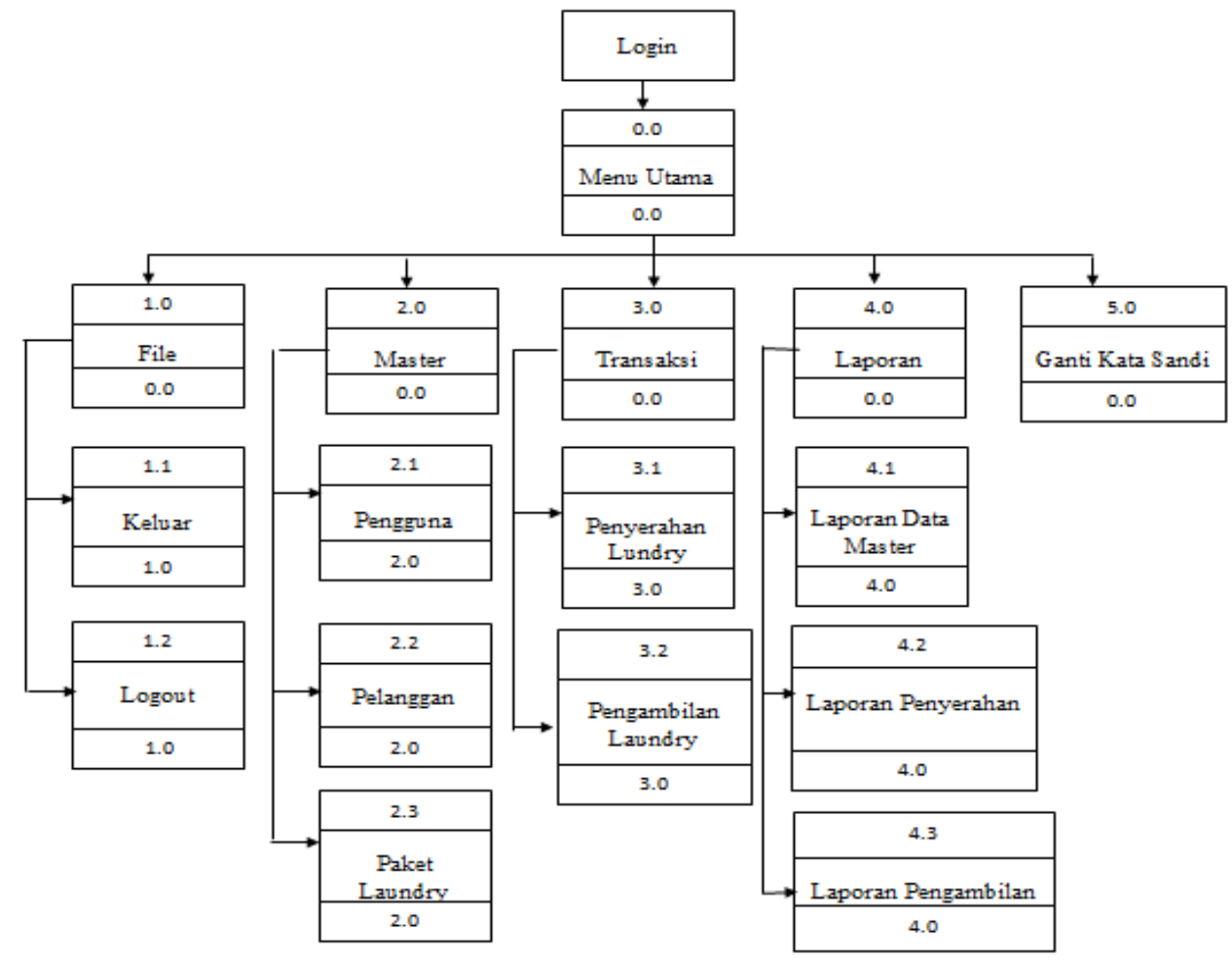

Gambar 12. HIPO Pengolahan Data Laundry 
Rumah Laundry

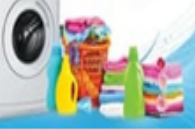

DATA PENYERAHAN LAUNDRY

JL. Merak III No. 115

Kelurahan Teluk Pucung, Kecamatan Bekasi Utara

No. Telp. 08561742903

Tanggal : 12 Desember 2018

\begin{tabular}{|l|l|l|l|l|l|l|}
\hline No Transaksi & Tgl Transaksi & Kode Pengguna & Kode Pelanggan & Tgl Selesai & Total & \multicolumn{1}{c|}{ Status } \\
\hline TR0918001 & $2018-09-12$ & PGA1807002 & PLG0618001 & $2018-09-12$ & Rp. 16.000 & Sudah diambil \\
\hline TR0918002 & $2018-09-12$ & PGA1807002 & PLG0618002 & $2018-09-12$ & Rp. 9.000 & Sudah diambil \\
\hline TR0918003 & $2018-09-12$ & PGA1807002 & PLG0718003 & $2018-09-12$ & Rp. 16.000 & Sudah diambil \\
\hline TR1018001 & $2018-10-12$ & PGA1807002 & PLG0718004 & $2018-10-12$ & Rp. 16.000 & Sudah diambil \\
\hline TR1018002 & $2018-10-12$ & PGA1807002 & PLG0718005 & $2018-10-12$ & Rp. 6.000 & Sudah diambil \\
\hline TR1018003 & $2018-10-12$ & PGA1807002 & PLG0718006 & $2018-10-12$ & Rp. 7.000 & Sudah diambil \\
\hline TR1118001 & $2018-11-12$ & PGA1807002 & PLG0618001 & $2018-11-12$ & Rp. 16.000 & Sudah diambil \\
\hline TR1118002 & $2018-11-12$ & PGA1807001 & PLG0618001 & $2018-11-12$ & Rp. 28.000 & Sudah diambil \\
\hline TR1118003 & $2018-11-12$ & PGA1807002 & PLG0618001 & $2018-11-12$ & Rp. 16.000 & Belum diambil \\
\hline TR1218003 & $2018-12-12$ & PGA1807001 & PLG0618001 & $2018-12-19$ & Rp. 16.000 & Belum diambil \\
\hline TR1218002 & $2018-12-12$ & PGA1807001 & PLG0618002 & $2018-12-19$ & Rp. 16.000 & Belum diambil \\
\hline TR1218001 & $2018-12-12$ & PGA1807001 & PLG0618001 & $2018-12-19$ & Rp. 16.000 & Belum diambil \\
\hline
\end{tabular}

Gambar 11. Laporan Data Penyerahan Laundry

\section{Pembuatan Kode Program}

Untuk membuat kode program penulis menggunakan bahasa pemrograman Microsoft Visual Studio Visual Basic. Net 2010. Dimana kode yang digunakan untuk mengklasifikasikan data, memasukan data ke dalam komputer dan untuk mengambil berbermacam-macam informasi yang berhubungan dengannya (Hartono, 2017:384385). Dalam pembuatan sistem informasi pengolahan data laundry ini digunakan struktur kode untuk setiap atribut key pada setiap entitas dengan struktur kode yang dapat mencirikan values dari atribut tersebut. Seperti contoh struktur kode untuk atribut notransaksi yang digunakan sebagai primary key saat penyerahan pakaian yang akan di laundry dan nostruk yang digunakan sebagai primary key ketika pengembalian pakaian. Adapun struktur kodenya sebagai berikut:

Struktur kode notransaksi

\begin{tabular}{|c|c|c|c|c|c|c|c|c|}
\hline$X$ & $X$ & 9 & 9 & 9 & 9 & 9 & 9 & 9 \\
\hline
\end{tabular}

Contoh:

\begin{tabular}{|l|l|l|l|l|l|l|l|l|}
\hline$T$ & $R$ & 1 & 8 & 0 & 6 & 0 & 0 & 1 \\
\hline
\end{tabular}

Struktur kode nostruk

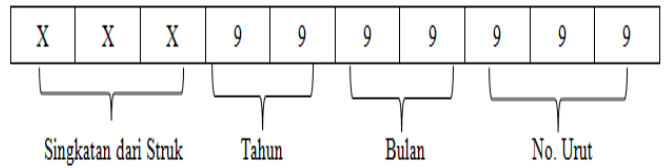

Contoh:

\begin{tabular}{|l|l|l|l|l|l|l|l|l|l|}
\hline$S$ & $T$ & $R$ & 1 & 8 & 0 & 6 & 0 & 0 & 1 \\
\hline
\end{tabular}

\section{Pengujian}

Setelah di desain tampilan program pengolahan data laundry, pada tahap ini program yang telah dibuat kemudian diujikan secara unit beserta kesesuaian dan kebutuhan serta kesalahan desain pada sistem informasi pengolahan data laundry serta diperiksa apakah adanya kesalahan sistem (bug) dalam pengujian kode program. Dilakukan integrasi terhadap database dengan kebutuhan menggunakan perangkat lunak mysql. Dengan pengujian sistem secara keseluruhan seperti pengujian terhadap keamanan dalam sistem informasi ini yang dilakukan oleh pengguna yaitu kasir dan admninstrasi. Pengujian terhadap program dari setiap menu dapat berjalan dengan baik yang digunakan pada PC sehingga dapat memudahkan pengguna dalam melakukan pengolahan data. 


\section{E. Support}

Pada tahap ini dilakukan sebuah perawatan serta memperbaharui sistemnya sesuai dengan perubahan data yang terjadi pada pengolahan data laundry, seperti perubahan data paket laundry, data penggunanya, dapat menampilkan laporan pengolahan data seracar rinci, serta menambahkan fitur-fitur yang dapat lebih memudahkan pengguna sesuai dengan kecanggihan teknologi.

\section{KESIMPULAN}

Berdasarkan hasil penelitian yang telah dilakukan maka dengan program pengelolaan data laundry ini dapat membantu serta mempermudah proses transaksi penerimaan jasa laundry pada rumah laundry. Dari mulai pendataan paket data laundry tercatat secara rinci, data pelanggan yang sudah menjadi data member, data penyerahan laundry serta data pengembalian laundry tanpa harus mencari-cari catatan-catatan sebelumnya sehingga menjadi lebih cepat dan akurat. Dengan adanya program ini rumah laundry dapat meningkatkan pelayanan kepada pelanggan dalam proses transaksi sehingga pelanggan setia dan percaya kepada rumah laundry.

\section{REFERENSI}

Andharsaputri, R. L. (2019). Perancangan Database Dan Sistem Informasi Terkomputerisasi Atas Siklus Pembelian. Journal Speed - Sentra Penelitian Engineering Dan Edukasi, 11(1), 42-50. Retrieved from http://ejurnal.pelitanusantara.ac.id/index.php/JIPN/ article/view/526/317

Dewi, M. A., Kurniati, D., \& Irmayani, W. (2017). Aplikasi Pelayanan Jasa Persediaan Bahan Baku Pada Laundry Q Pontianak. Jurnal Khatulistiwa Informatika, V(2), 112-117. Retrieved from http://ejournal.bsi.ac.id/ejurnal/index.php/ khatulistiwa/article/view/2927

Fatmawati. (2016). Perancangan Sistem Informasi Pemesanan Katering Berbasis Web Pada Rumah Makan Tosuka Tangerang. II(2), 3341. Retrieved from http://ejournal.bsi.ac.id/ejurnal/index.php/j tk/article/view/1609

Frediyatma, S. Y. (2014). Aplikasi Pemesanan Makanan Berbasis Cloud dengan Platform Android. Jurnal MERPATI, 2(1), 118-126. Retrieved from https://ojs.unud.ac.id/index.php/merpati/ar ticle/view/17832/11587
Hartono, J. (2017). Analisis dan Desain (Sistem Informasi Pendekatan Terstruktur Teori dan Praktek Aplikasi Bisnis). Yogyakarta: Andi Offset.

Hasugian, P. M. (2019). Perancangan Sistem Pendukung Keputusan Dalam Menentukan Dosen Berprestasi Dengan Metode Simple Additive Weighting. Journal of Informatic Pelita Nusantara, 1(1), 33-37. Retrieved from http://e-

jurnal.pelitanusantara.ac.id/index.php/JIPN/ article/view/526/317

Helling, L. S. (2018). Perancangan Sistem Informasi Pelayanan Pelanggan Pada Citra Laundry Bogor. INTENSIF: Jurnal Ilmiah Penelitian Dan Penerapan Teknologi Sistem Informasi, 2(1), https://doi.org/10.29407/intensif.v2i1.1179 2

Karman, J., \& Nurhasan, A. (2019). Perancangan Sistem Keamanan Data Inventory Barang Di Toko Nanda Berbasis Web Menggunakan Metode Kriptografi Vigenere Cipher. Jurnal Teknologi Informasi MURA, 11(1), 29-36. Retrieved from http://jurnalstmik.muralinggau.ac.id/index.php/jti/issue /view/45

Khoirunnissa, R., Isnanto, R. R., \& Martono, K. T. (2016). 12691-25708-1-Sm. Jurnal Teknologi Dan Sistem Komputer, 4(1), 93-101. Retrieved from https://jtsiskom.undip.ac.id/index.php/jtsis kom/article/view/12691

Kirlyana, B., \& Rosyida, S. (2016). Sistem Informasi Penjualan Sepatu Handmade Berbasis Web. Information Management for Educators and Professionals, 1(1), 22-31. Retrieved from http://www.ejournalbinainsani.ac.id/index.php/IMBI/article/vie $\mathrm{w} / 153$

Puspitasari, D. (2014). Sistem Informasi Rekam Medis Pada "Cardiac Centre Herman Toni" Di Karawang Dengan Model Water Fall. Jurnal Pilar Nusa Mandiri, X(1), 81-94. Retrieved from

http://ejournal.nusamandiri.ac.id/ejurnal/in dex.php/pilar/article/view/103

Rosyida, S., \& Riyanto, V. (2018). Sistem Informasi Pengelolaan Data Laundry Pada Rumah Laundry Bekasi. In Laporan Akhir Penelitian. 
Bekasi.

Saggaf, S., Salam, R., Kahar, F., \& Akib, H. (2014). Pelayanan Fungsi Administrasi Perkantoran Modern. Jurnal Administrasi, 1(1), 21-27. Retrieved from http://ojs.unm.ac.id/index.php/administrare /article/viewFile/877/196

Sukamto, R. A., \& Shalahuddin, M. (2015). Rekayasa Perangkat Lunak Terstruktur dan Berorientasi Objek. Bandung: Informatika.

Sulianta, F., \& Umbara, F. R. (2015). Teknik Hebat Merancang Aplikasi Instan dan Berkualitas. Jakarta: PT Elex Media Komputindo.
Sari, E. N., Handayani, L., \& Saufi, A. (2017). Hubungan Antara Umur dan Masa Kerja dengan Keluhan Musculoskeletal Disorders (MSDs) pada Pekerja Laundry. Jurnal Kedokteran Dan Kesehatan, 13(2), 183. https://doi.org/10.24853/jkk.13.2.183-194 